\title{
THE EVOLUTION AND DEVELOPMENT OF MECHANICAL ENGINEERING THROUGH LARGE CULTURAL AREAS
}

Emilio Bautista Paz, Marco Ceccarelli, José Luis Muñoz Sanz, Javier Echávarri Otero, Pilar Lafont Morgado, Andrés Díaz Lantada, Pilar Leal Wiña, Héctor Lorenzo-Yustos, Juan Manuel Munoz-Guijosa, Julio Muñoz-García

Grupo de Inv. en Ingeniería de Máquinas - Universidad Politécnica de Madrid E-mail: jlmunoz@etsii.upm.es / jechavarri@etsii.upm.es / adiaz@etsii.upm.es

\begin{abstract}
Mechanical Engineering is probably the forerunner of many branches of Engineering and has persistently been their companion up to the present. For this reason, the History of Machines embraces a very broad period of the History of Mankind, and can be studied from many perspectives. This paper attempts to link progress in Mechanical Engineering to the great cultures that have arisen throughout the History of Mankind.

This paper begins with the anonymous mechanical developments that appeared in Prehistory and opened up the way to the first civilisations, marked to a large extent, maybe, by Greco-Roman culture in Europe and by China in Asia. After them came the Islamic world, which, in the Middle Ages stimulated society to find new mechanical devices and set the foundations that would lead to the Renaissance. Outstanding in this period was the expansion of Italian, French and German creative and innovative thinking with its "Treatises on Machines", which, for a short time, coincided with the advance of the Iberian Empire and the development of machinery for the New World. Finally, the Industrial Revolution became the climax of all previous developments and a period of rapid mechanical evolution began that was to be highly interesting from a historical and technological point of view. This was accompanied by a parallel interest in reflecting on and analysing machines, which has led to the appearance of countless “Treatises on Machines”.
\end{abstract}

KEYWORDS: History, Machine, Treatise on Machines, Cultural Area. 


\section{INTRODUCTION}

The History of Mankind is also the History of Technology. Any culture moves forward at a rhythm imposed by its technology. Scientific knowledge itself requires a pre-existing technological substratum in order to move forward. Political and military affairs are also underpinned by technological development. Economic history goes hand in hand with the technological development, products and transport that make trade possible. On both a large and small scale, Engineering takes advantage of the existing technology of every period and makes it tangible. Engineering makes technological knowledge a reality and places it at the service of society by creating useful objects.

Mechanical Engineering is, together with Architecture, Civil and Military Engineering, the forerunner of newer types of engineering, which means the History of Machines embraces a very extensive period of the History of Mankind, all of which makes compiling a Machine Compendium extremely difficult. An eight section framework has been chosen, each section of which more or less corresponds to historical periods focused on large cultural areas; this inevitably leads to time overlaps. Each period receives a cultural inheritance from the previous ones and each culture receives cultural influences from other cultural areas, but the overall result is a compendium that presents a reasonably coherent sketch of the global development of the human race. This point of view has been dealt with in the book entitled "A Brief Illustrated History of Machines" [1] published by the authors, where the contents and chapters are set out in this paper are dealt with in more detail.

In general, a whole range of Prehistoric devices exist under the chapter name of ANONYMOUS DEVELOPMENTS, whose inventors, for many reasons, are unknown to us. The Neolithic revolution also has a part in the anonymous development of machinery.

Looking at historical epochs, the great Mesopotamian river cultures, of southeast Asia or the Chinese plains, developed mechanical devices after they had discovered the written word. The Chinese cultural area that spread from the Ancient World to the beginning of Modern Times has been chosen in order to describe CHINESE INVENTIONS AND MACHINES.

Likewise, Greco-Roman culture is of particular relevance for MECHANICAL ENGINEERING IN ANTIQUITY. Latin and Greek have always been accessible languages for western European peoples, for which reason most references to Middle Eastern and North African cultures originate from Greek and Roman authors, who lived in, and came into direct contact with extensive cultural zones of the ancient world. The influence of this ancient world reached out to the Middle Ages passing through Byzantium and Islam and penetrated the Renaissance with the study of authors such as Vitruvius.

So the way was opened up for MEDIEVAL MACHINES AND MECHANISMS where Arab authors were outstanding, since Islam spread to the confines of the known world during the Middle Ages, and Arabic became the vehicle of culture in its area of influence. 
The title, THE MACHINE RENAISSANCE refers to the tremendous impulse given, mainly from Italy, to all spheres of knowledge and also to the study of machines. Thus a considerable technological difference began to be marked between European culture and other cultures, which has lasted up to present times.

Additionally the technological impulse of the Renaissance led firstly to the great geographical discoveries and then to the founding of the European colonial empires that spread to large parts of the world. Very soon after, the MACHINES OF THE FIRST IBERIAN COLONIAL EMPIRES took advantage of the technological achievements of the Renaissance in order to exploit the resources at their disposal.

European political policy boosted industrial development by creating new ever more science-based technologies. The abundant MACHINERY OF THE INDUSTRIAL REVOLUTION reflects the achievements attained in this period. Technology was the travelling companion of political hegemony.

Recent history, particularly that referring to machines, has been considered to be sufficiently known, and therefore lacking in the "historical" interest that remote periods might have. On the other hand, the increasing speed at which technology is developing would make any systematic processing of the present-day period difficult and certainly ephemeral.

However, after the Industrial Revolution, an unusual event took place in Europe that marked a difference in respect of what happened in other cultures: A REFLECTION ON MACHINES mainly led by the French enlightenment whose influence at the time spread to all European countries. These Reflections obviously had roots in the past, mainly in the Renaissance, and gave rise to systematisations for ever more mathematically-based personal machine study, which resulted in this material being included in higher study programmes. We are of the opinion that this qualitative leap deserved a separate chapter.

\section{ANONYMOUS DEVELOPMENTS}

No matter how far back in time we go, there is a considerable number of machines and mechanisms that are common cultural heritage. These study of ancestral developments is relate to two basic areas: Archaeology and Biology.

Archaeology has enabled the mechanisms used since Prehistory to be discovered through an exhaustive analysis of the remains from sites. These remains are not usually one object but an ordered set of parts, which gives rise to different theories and interpretations resulting from the innumerable studies carried out. Moreover, it is unusual for any archaeological remains to be found intact, which means that an adequate interpretation of many of them is difficult, particularly as the concept of a machine is linked to the relative motion of the various constitutive parts. Although current Archaeology lends more importance to the context of a site than to the object in isolation, there continues to be an intrinsic difficulty in recognising various scattered, incomplete parts as being the parts of a mechanism. 
The examples of machine development resulting from collective, popular resourcefulness in prehistoric times are innumerable. Figure 1.a shows a prehistoric drill, compiled by Strandh in 1998 [2].

As for the biological axis, it may be said that the most important development of anonymous mechanisms was based on biological shapes, as highly effective mechanisms can be found in both plants and animals. Their variety, complexity and evolution are also irrefutable evidence of mechanical design that induces us to include these "biological mechanisms" in the History of Machines. Figure 1.b shows the hearing "mechanism" of a grasshopper, depicted by Hass in 1979 [3].

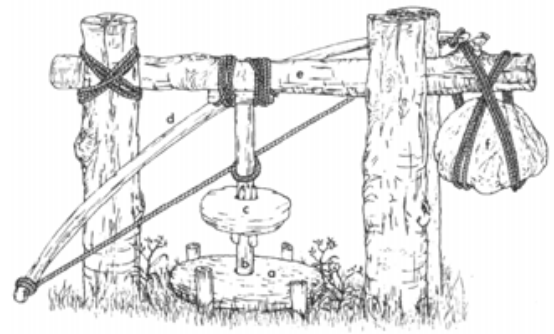

a)

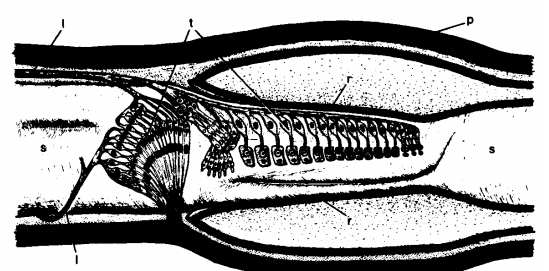

b)

Fig. 1. a) Bow drilling machine. Reconstruction from "Machines, an Illustrated History" by Sigvard Strandh. b) Ear in a grasshopper's front leg, from "From Fish to Man” by H. Hass.

\section{CHINESE INVENTIONS AND MACHINES}

Ideographic writing and a concern for calligraphy has been successful in revealing that Chinese technology had surprisingly evolved, on many occasions, beyond what was to be found in Europe up to the 16th century. Extremely ancient documents like the "Kao Gong Ji" ("Book of Diverse Arts", 770-221 BC), reveal a concern for the development of science in all its forms: Astronomy, Biology, Mathematics, Physics and Engineering.

Numerous written examples followed this work: compendiums on war machines, agricultural and hydraulic machines, textile machinery, clocks and automatons follow one another through countless pages of diagrams and explanations. Two excellent examples of this technological progress are shown in Figure 2: "the south pointing chariot", a series of gears and gear wheels that always kept the figure's finger pointing south, which dates from 2600-1100 BC and Su Song's astronomical clock built in 1089, which, with its more than four hundred parts was undoubtedly a technological wonder. Additional examples can be found in the book "Qi Qi tu Shou" by Schreck and Wang Cheng which includes copies, sketches and improvements of machines from the European Renaissance. 


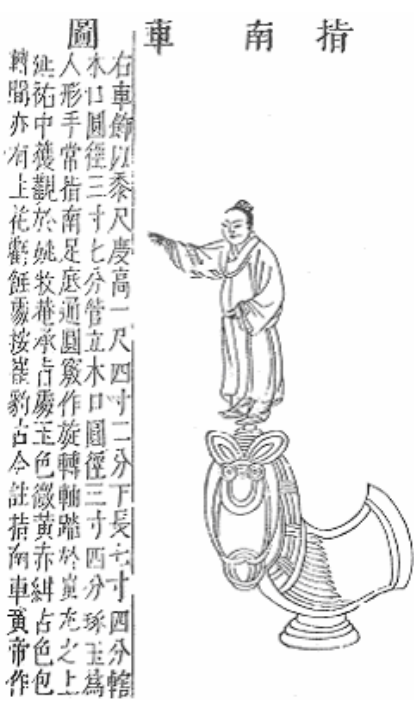

a)

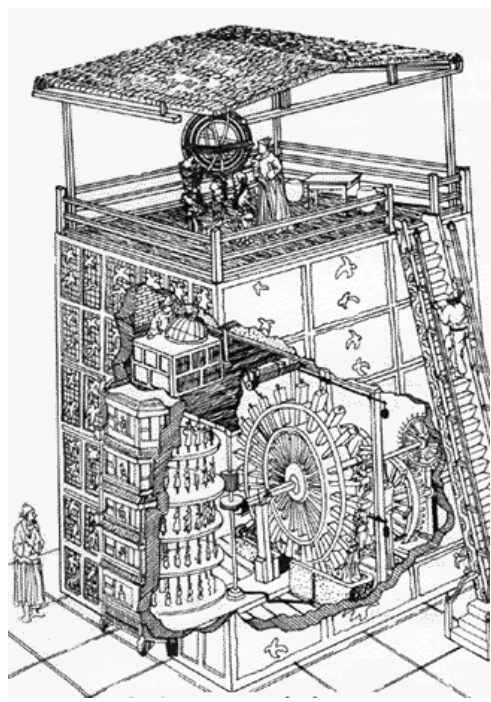

b)

Fig. 2. a) Drawing of the "south pointing chariot" from the "San Tshai Thu Hui" [4] by Wang Chhi, 1609. b) Su Song's astronomical clock from the "History of the Sung Dynasty” [5] by Shen Yueh, 500 AD.

\section{MECHANICAL ENGINEERING IN ANTIQUITY}

Some documents, artistic representations, and even humanistic literature reveal the existence of numerous automatic mechanisms during Antiquity, although most of them not been preserved, The Greco-Roman world adopted a large part of the technology developed by previous cultures such as the Egyptian civilisation.

Greece attained a high level in technical fields, one of the most outstanding examples being the School of Alexandria (from the $3^{\text {rd }}$ century BC), where celebrities as famous as Archimedes, Euclid, Philo (fig 3.a) and Hero received their training. Some historians consider the latter to be the first real engineer because of his detailed and precise diagrams and explanations. His work entitled "Pneumatics" [6] brings together a series of automatic machines that were studied not only during his time, but subsequently rediscovered and used during the Renaissance.

The evolution of Greek culture had a determining influence on Roman technology. Its technology became more in-depth and wider-ranging with a study of different fields like public works and military applications. The most remarkable figure of this period was undoubtedly Vitruvius (80-70 BC. -25 BC.) with his "De Architectura” [7], a work containing his knowledge on architecture, including explanations and drawings of the machines used for this craft. This book was reproduced during Renaissance by authors like Daniele Barbaro and many others. Figure 3.b shows a later representation by J. de Ortiz y Sanz from 1787 [8]. 


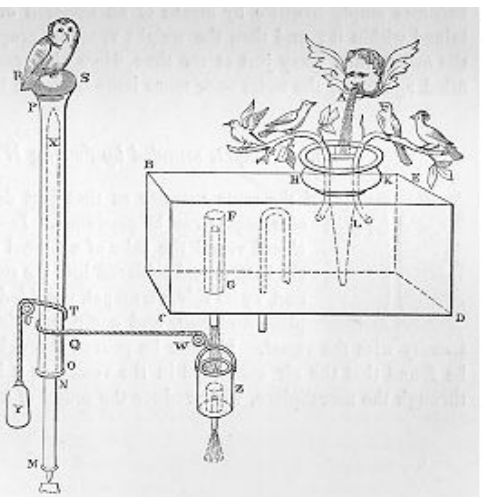

a)

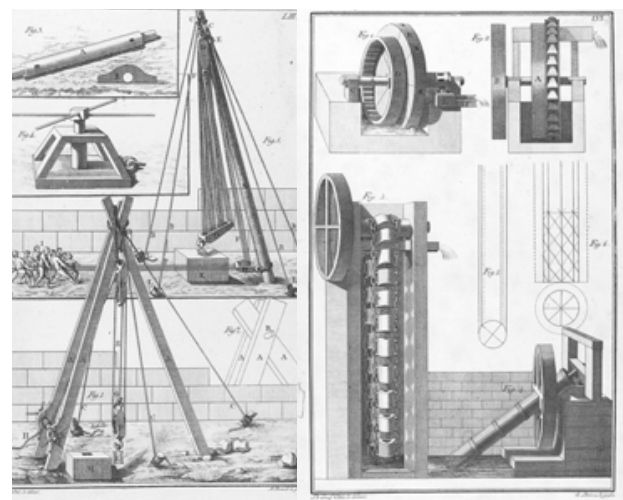

b)

Fig. 3. a) Hero's "Singing birds" from Bennet Woodcroft's translation of "Pneumatics”[6], 1851. b) Reconstruction of machines for raising water and loads from Vitruvius’ book, by J. Ortiz y Sanz [8], 1787.

\section{MEDIEVAL MACHINES AND MECHANISMS}

Islam spread to the confines of the known world during the Middle Ages and Arabic became the vehicle of culture in its area of influence. The "House of Wisdom", founded in Baghdad (9th C), contributes to the apparition of the book entitled "Ingenious Devices" [9] written by the three Banu Musa brothers, whose pages contain the diagrams of one hundred machines and mechanisms. Some machines were copies of those produced by Hero and Philo but many others were improvements of these or new models.

Following in their footsteps came the most significant name in Islamic technology: Al-Jazari (1136-1206). His "Book of Knowledge of Ingenious Mechanical Devices” [10], [11] shows fountains, clocks, water wheels and automatons with a precision of detail in both drawings and explanations that had been unknown up to that time. His machines reveal an increasing complexity that turned out to be not only useful but also of spectacular appearance, as was the case of the elephant clock that combines mechanical engineering and design in equal parts. Figure 4 presents two examples of machines from the cited Al-Jazari's book. 


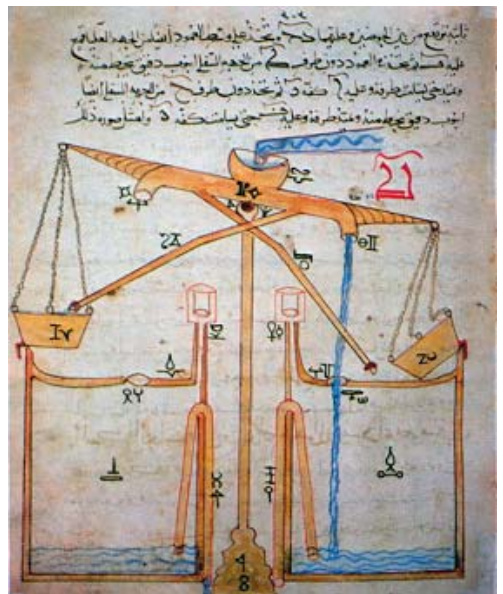

a)

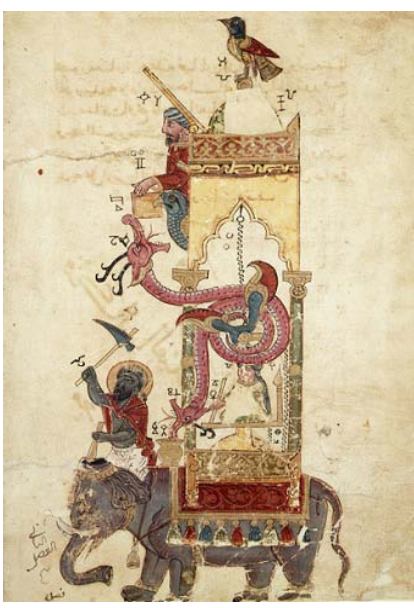

b)

Fig. 4. a) Fountain. b) Elephant clock. Both from the Book written by Al-Jazari.

Although it was the Islamic world that most disseminated its knowledge, Europe was moving slowly forward along the road to the Renaissance. Walking this road was Villard de Honnecourt, who, in the 13th century, produced a notebook [12] where he drew the machines and mechanisms he had seen on his travels, such as catapults, saws and lifting devices.

\section{THE MACHINE RENAISSANCE}

The Re-birth of Western Europe in the14th, 15th and 16th centuries marked a stage of renewed activity and vitality on a level of arts, sciences and literature, as it was sought to leave behind the stagnation of the Middle Ages. Unlike what happened in the Middle Ages, the opening up of Renaissance society paved the way to the spread of machines.

The 15th century can be taken as the high period of machine development, with celebrities like Leonardo da Vinci [13], [14] and Francesco Di Giorgio [15], whose success was partly due to an environment that was open to their creativity and new ideas. Parallel to this an interest in the theoretical aspects of machines led to a recovery of the knowledge of Antiquity with the study of authors from the Greek and Roman culture.

The publication of knowledge in the form of treatises began at the end of the 15th century. A first line of activity was the study of machine mechanics as an application of physics, by well-known figures such as Guidobaldo del Monte [16], [17] and Galileo Galilei [18]. The second line consisted of a development towards a discipline in the shape of a rational collection of machines, outstanding of which 
were the machine collections of the aforementioned Francesco Di Giorgio and Agostino Ramelli.

The Machine Renaissance, from Italy, spread throughout Western Europe from the second half of the 15th century with outstanding works such as Georgius Agricola's "De Re Metallica" [19] and Jacobus Strada's "Kunstliche Abris allerhand Wasser" [20]. Figure 5 shows the title pages of some relevant "Machine Treatises.”
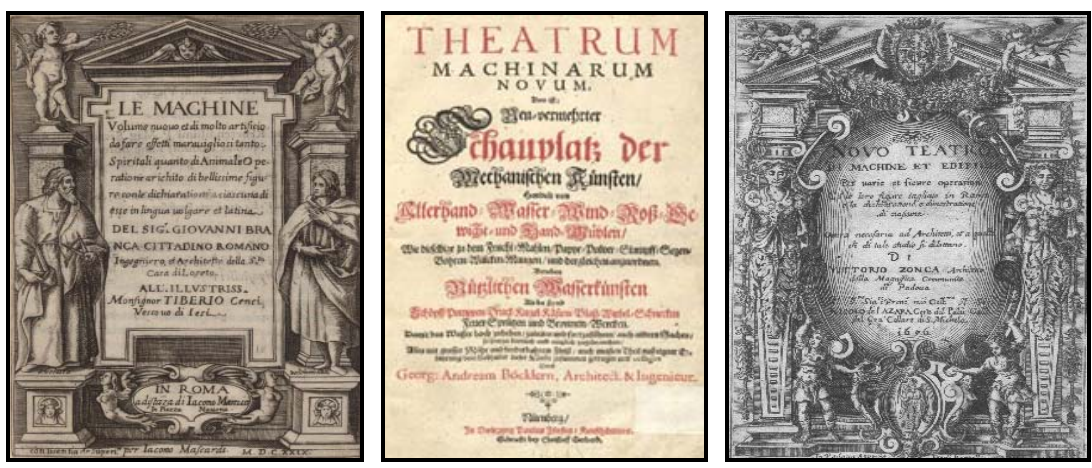

Fig. 5. Title pages of some "Machine Treatises" [21], [22], [23].

The printing press was a decisive factor in the dissemination of these treatises. Not only the text but also the accompanying illustrations attained a quality hitherto unknown in the previous books on machines that had been painstakingly copied by scribes. Although some significant treatises have survived to the present in the form of manuscripts, most authors published printed books whose readers no longer needed to belong to the privileged classes. Machine knowledge became popular and spread on a qualitatively different scale from previous periods.

\section{MACHINES IN THE FIRST COLONIAL EMPIRES}

For various known historical reasons, in Modern Times Europe set out on a process of expanding its political and cultural influence over large geographical areas, founding European colonial empires that have endured to the present. In this sense, Castile and Portugal had overtaken all other European nations from the end of the 15th century, which meant that the first colonial empires were basically Iberian.

Going round the world was a feat requiring mechanical engineering, but keeping the new spice trade routes open meant that engineering was here to stay. The overseas mineral resources needed new machinery to exploit them. All this gave rise to specific centres for the study of science and technology, which facilitated this global geographic expansion. 
Further clear proof of the strategic interest in mechanical engineering was the publication of Juanelo’s “The Twenty-One Books of Devices and Machines” [24], ordered written by "the Catholic King Philip II, King of Spain and the New World", in about 1570. Among other knowledge, the book contains a large number of machines of the time ordered according to function with a surprising number of pumps, mills, cranes and other machines, particularly those driven by water, wind-energy, gravity or animal traction.

Considered to be a machine encyclopaedia by many historians, the author of this work is unknown. Since Juanelo Turriano was famous at the time for being the inventor of a well-known device in Toledo for raising water called "the dancing machine” (Figure 6.a), it was initially attributed to him. However, later studies have shown that it might have been by Pedro Juan de Lastanosa [25].

Other outstanding figures were Jerónimo de Ayanz y Beaumont [26], who was awarded a patent in 1606 for over fifty devices and Francisco Lobato [27], who, in less than forty pages made notes on technology from 1547 to 1585.

Figure 6.b below, of one of the most common and used machines of the period, is shown by way of example: the mill. In this example, it was convenient to be able to adjust the height of the water wheel and adapt the position of the paddles according to the level of the water.

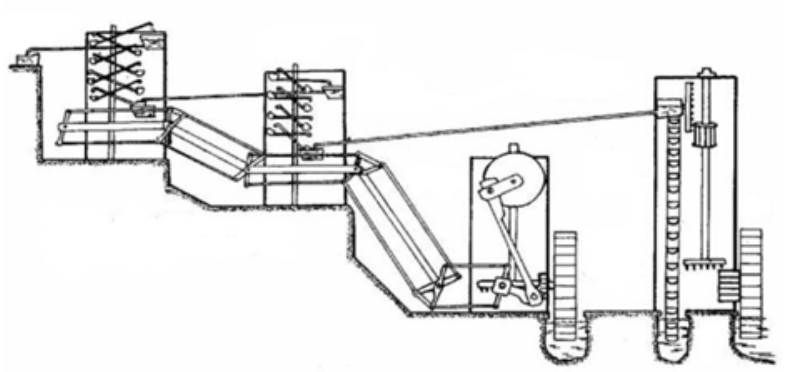

a)

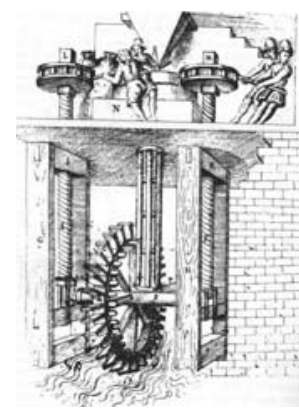

b)

Fig. 6. a) Diagram of Juanelo’s device in Toledo: “The dancing machine”. Reconstruction by L. Reti. b) Mills from "The Twenty-One Books of Devices and Machines”, 1570.

\section{THE MACHINERY OF THE INDUSTRIAL REVOLUTION}

This period in history arose after the accumulation of knowledge from preceding eras and due to the coming together of a series of factors that resulted in a period of continuous advancement and progress that led to a change of focus, both social and engineering.

The construction of the steam engine by J. Watt (1736-1819) was a turning point, but on a mechanical level maybe establishing the search for automation in every field was more important. The machines began to replace people as a result 
of the new technologies that were being discovered in agriculture, mining or textile industry. A fine example of this generalised progress came about in the sphere of textile engineering, where developments arose in every field (spinning, weaving and sewing), thanks to men like Arkwright, Hargreaves and Crompton [28].

Figure 7 shows two examples of these machines: Arkwright's "Water frame" (or continuous motion machine) and Hargreaves' "Spinning Jenny". Evolution was continuous and in very few years all industries that were unable to move forward with technology became obsolete.

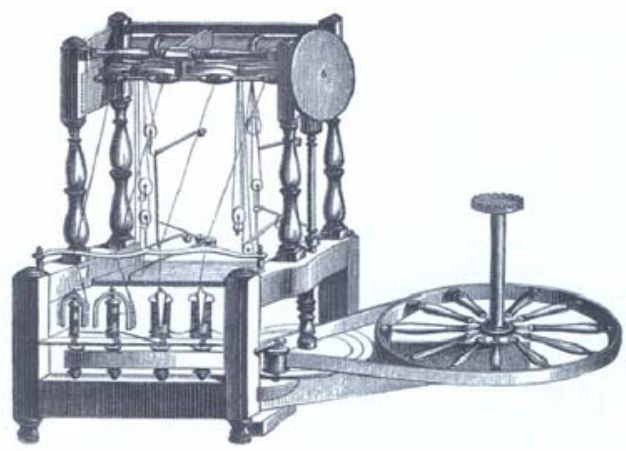

a)

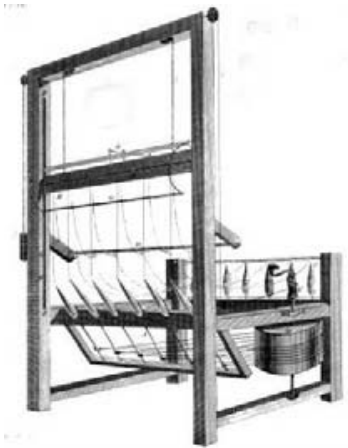

b)

Fig. 7. a) Arkwright’s “Water frame”. b) Hargreaves’ “Spinning Jenny”.

It should also be emphasised that the industrial revolution did not spread and appear everywhere at the same speed. For example, while England was the pioneer in introducing mechanised and automated industries, neighbouring France was caught up in a social conflict that set it aside from this type of progress.

\section{A REFLECTION ON MACHINES}

Throughout the above section, it has been seen how machines evolved alongside the cultural, social and often political circumstances. After the Industrial Revolution, mechanical development embraced a whole range of subjects.

Even so, after the Industrial Revolution, there appeared, or rather, reappeared, a new "History of Machines": one made up of the theoretical treatises begun in the Renaissance but consigned to oblivion by the writings of the French Enlightenment, and which set out a series of essays and treatises on the composition of mechanisms and machines or theoretical studies of mechanical models.

One of the first was by the Spaniard Agustín de Betancourt, who moved to France to study. In his “Essay on Machine Composition” [29] (together with José María de Lanz) he puts forward a classification of movements which still continues to be valid. 
Many are the engineers who followed in his footsteps: M. Hachette [30], J. Weisbach [31], Labouyale [32], F. Redtenbacher [33] and F. Reuleaux [34], [35], not only used the books of their time but also those of their much older predecessors, such as G. del Monte [16], [17] and G. Galilei [18] who, in the midst of the Renaissance, took it upon themselves to reflect on the study of Mechanics.

From modern authors the works of Artobolevsky on "Modern Technical Mechanisms" and Needham on "Chinese Engineering” are really noteworthy.

Figures 8 and 9 include a few examples, by different authors, regarding remarkable contributions on the machines and mechanism science.

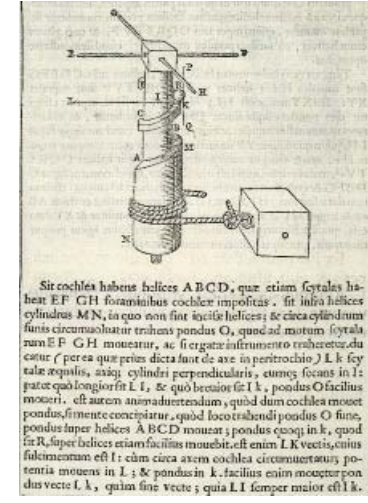

a)

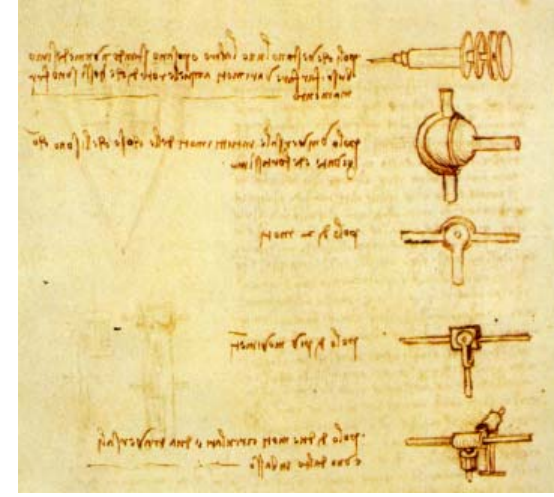

b)

Fig 8. a) Page from "Le Mechaniche” by G. Del Monte, 1581 [16]. b) Machine classification from "Madrid Codex” by L. Da Vinci, 1493 [14].
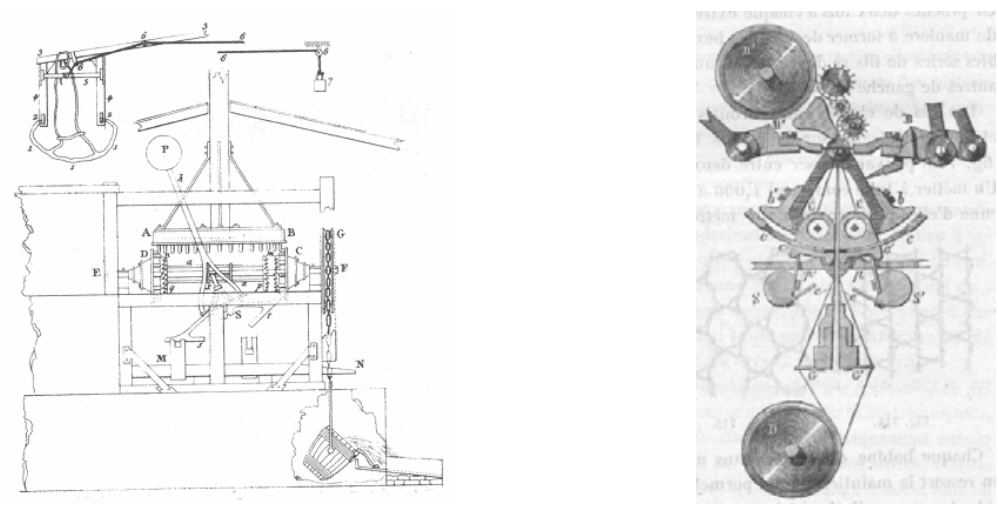

Fig 9. a) Figure from "Essay on Machine Composition” by A. de Betancourt and J.M. de Lanz [29], 1808. b) Mechanism from “Traité de cinématique” by Labouyale, 1861 [32]. 


\section{Conclusions}

Comparing the "History of Mankind" with the "History of Machines" reveals a parallel evolution that results in political and economic hegemony going along with the most technologically developed cultures. Technical progress has led man to use his imagination and resourcefulness not only for his own benefit but also as a way of providing help in tasks or work requiring skilled operatives. This work has always been done jointly and under the considerable influence of the scientific and political environment of the time. Perhaps the most appropriate example of this type of development is the Industrial Revolution, which, as we have seen, gave way to automated industries and the replacement of men by machines.

A "History of Machines" will never be complete, but this lightweight review [1] will help understand how the minds of "mechanical engineers" gradually evolved and changed, adapting to their era while looking to a "beyond" that led them to discover new and improved machines and mechanisms that would become a new step on an endless flight of stairs.

\section{References}

1. Bautista E, Ceccarelli M, et al. (2006) Breve Historia Ilustrada de las Máquinas, Sección de Publicaciones de la E.T.S.I.I. Universidad Politécnica de Madrid.

2. Strandh S (1998) Machines: Una historia ilustrada, Raíces.

3. Hass H (1979) Del pez al hombre, Salvat.

4. Chhi W (1609) San Tshai Thu Hui.

5. Yueh S (500) History of the Sung Dynasty.

6. Woodcroft B (1851) Pneumatics.

7. Vitruvius PM (1511) De architectura, Published by Fra Giocondo, Verona (reprinted in 1513, 1522 and 1523).

8. Ortiz y Sanz J (1787) Tratado sobre máquinas de Vitruvio, 1787.

9. Banu Musa, The book of ingenious devices: Kitab Al-Hiyal, $10^{\text {th }}$ Century.

10. Al-Yazari, Al-Zaman (1974) The Book of Knowledge of Ingenious Devices, D. Reidel Publishing Co..

11. Hill D (1998) Studies in medieval Islamic technology: from Philo to al-Jazari: from Alexandria to Diyar Bakr, Variorum Reprints.

12. V de Honnecourt (1991) Cuaderno. Siglo XIII, Akal.

13. L da Vinci, Atlantic Codex, 15th Century.

14. L da Vinci (1493) Madrid Codex, 1493.

15. F di Giorgio, Trattato di architectura e machine, 15th Century.

16. G del Monte (1577) Mechanicorum Liber.

17. G del Monte (1581) Le Mechanique.

18. Galilei G (1643) Les Mechaniques, Re-published by Brunetti, Turin, 1964.

19. Agrícola G (1556) De re metallica, Reprinted in 1950 by Dover Publishing. 
20. Strada J (1617) Kunstliche Abrís allerhand Wasser - Wind Rosz- und Handt Muhlen, Gedruckt durch Paulum Iacobi in Verlegung Octavii de Strada.

21. Branca G (1629) Le machine.

22. Böckler G (1661) Theatrum Machinarum Novum, In Verlegung Paulus Fürsten, Gedruckt bey Christoff Gerhard.

23. Zonca V (1607) Novo teatro di machine et edificii per uarie et sicure operationi, Appresso Bertelli.

24. Anonymous (1570) The 21 Books of devices and Machines, (Published in 1997 in Spanish and English in a 7 volume edition), Fundación Juanelo Turriano.

25. García Tapia N (1988) Pedro Juan de Lastanosa y Pseudo Juanelo Turriano.

26. García Tapia N (2001) Un inventor navarro. Jerónimo de Ayanz y Beaumont, Departamento de Educación y Cultura de Pamplona.

27. García Tapia N y García Diego JA (1990) Vida y Técnica en el Renacimiento: Manuscrito by Francisco Lobato, of Medina del Campo, in the 16th century, Valladolid : Secretariado de Publicaciones, D.L..

28. Various authors (1993) Crónica de la técnica, Plaza y Janés.

29. Lanz J, Betancourt A (1808) Ensayo sobre la composición de las máquinas, Editorial Castalia, Colegio de Caminos, Canales y Puertos.

30. Hachette M (1811) Traite Élémentaire des Machines, Corby.

31. Weisbach J (1848) Principles of the Mechanics of Machinery and Engineering, Lea and Blanchard.

32. Labouyale (1861) Traité de cinématique ou Théorie des mécanismes, E. Lacroix.

33. Redtenbacher F (1866) Die Bewegungs-Mechanismen, Heidelberg.

34. Reuleaux F (1875) Kinematics of Machinery, F. Savy.

35. Reuleaux F (1876) Lehrbuch der Kinematik, V.1 Theoretische Kinematik, F. Savy. 